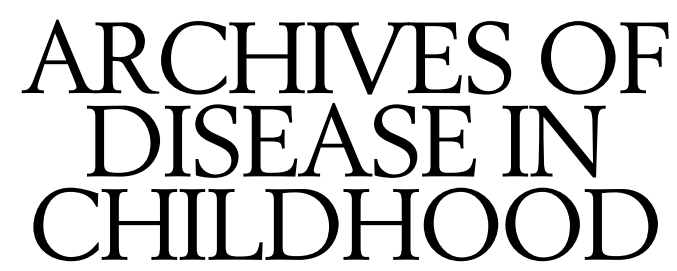

The fournal of the Royal College of Paediatrics and Child Health

\title{
Early growth and cardiovascular disease
}

Ten years ago studies in Britain showed for the first time that people who had low birth weight were at increased risk of coronary heart disease and the disorders related to it: stroke, non-insulin dependent diabetes, raised blood pressure, and the metabolic syndrome. ${ }^{1-3}$ In a study of 16000 men and women born in Hertfordshire death rates from coronary heart disease fell twofold between those at the lower and upper ends of the birth weight distribution. In groups investigated clinically the prevalence of noninsulin dependent diabetes and impaired glucose tolerance fell threefold. Such findings led to the "fetal origins hypothesis", which states that cardiovascular disease and non-insulin dependent diabetes originate through adaptations that the fetus makes when it is undernourished. ${ }^{4}$ These adaptations, which include slowing of growth, permanently change the structure and function of the body.

Recently, associations between low birth weight and later disease have been widely replicated in studies in Europe and the USA. ${ }^{5-7}$ These studies have also confirmed that the associations are not the result of confounding variables, such as low socioeconomic status and smoking, which act in postnatal life. Influences that act in postnatal life do, however, add to the effects of low birth weight. For example, the highest prevalence of non-insulin dependent diabetes is found in people who had low birth weight but were obese as adults. ${ }^{2}$ Replication of the associations between low birth weight and later disease in large studies such as the American nurses' study has been possible because most adults are able to discover their birth weights from parents or other relatives. ${ }^{6}$ However, while birth weight serves as a marker of fetal growth it is a crude one. The same birth weight may be the outcome of many different paths of growth. ${ }^{8}$ Furthermore, findings among people who were in utero during the Dutch famine show that the fetus' metabolism may be permanently changed by levels of undernutrition that do not affect fetal growth. ${ }^{9}$ This finding has important public health implications as it suggests that associations with body size at birth underestimate the contribution of intrauterine development to later disease.

\section{Body proportions at birth and adult disease}

Further insight into fetal responses to undernutrition and their long term consequences has come from studies where detailed measurements of size at birth, including length, head circumference, and placental weight, were available.
Four birth phenotypes associated with later disease have been identified. ${ }^{10}$

THIN

Babies that are thin tend to be insulin resistant as children and adults, and are therefore liable to develop the insulin resistance syndrome. ${ }^{11}$ One interpretation of this is that the thin baby has adapted to undernutrition through endocrine and metabolic changes.

SHORT

Babies that are short in relation to their head circumference, and have a reduced abdominal circumference, tend to have persisting abnormalities of liver function, including raised serum LDL cholesterol and plasma fibrinogen concentrations. ${ }^{12}{ }^{13}$ Replication of these observations has, however, been limited because few datasets include abdominal circumference at birth. Babies that have a small abdominal circumference in relation to their head circumference can result from "brain sparing" circulatory adaptations by which cardiac output is diverted to the brain at the expense of the trunk. ${ }^{14}$

SHORT AND FAT

Studies in southern India have shown that babies who are short and fat tend to become insulin deficient and have high rates of non-insulin dependent diabetes. ${ }^{15}$ This is consistent with findings in Pima Indians and with observations in Sheffield that showed a U-shaped association between abdominal circumference at birth and death from coronary heart disease. ${ }^{16}{ }^{17}$ Babies that are short and fat are thought to be the result of maternal hyperglycaemia, with consequent imbalance in the supply of glucose and other nutrients to the fetus.

\section{LARGE PLACENTA}

Studies in Preston showed that babies whose placentas are disproportionately large in relation to their own weight tend to have raised blood pressure. ${ }^{18}$ While this has been replicated in other studies it has not been found consistently; in a study in Aberdeen, raised blood pressure was associated with small placental size. ${ }^{19}$ Animal studies offer a possible explanation. In sheep the placenta enlarges in response to moderate undernutrition in mid-pregnancy. This is thought to be an adaptive response to extract more nutrients from the mother. It is not, however, a consistent 
response but occurs only in ewes that were well nourished before pregnancy.

\section{The malnourished fetus}

The weight of evidence from studies of the birth weights of relatives has led geneticists to conclude that, although the growth of a fetus is influenced by its genes, it is usually limited by the nutrient and oxygen supply it receives. ${ }^{100}$ Constraint of fetal growth by the mother has been shown in embryo transfer and cross breeding experiments; a fetus transferred to a larger uterus will achieve a larger birth size. A study of babies born after ovum donation showed that while their birth weights were strongly related to the weight of the recipient mother, they were unrelated to the weight of the woman who donated the egg. ${ }^{21}$ It has been suggested that the associations with low birth weight reflect genes that determine both reduced fetal growth and later disease. The known plasticity of fetal growth and its control by the mother makes this speculation improbable. Rather there is a clear need to study interactions between genes and nutrient supply in utero. This focus on the nutrient supply to the fetus is supported by numerous animal experiments showing that poor nutrition may permanently affect the structure and physiology of the fetus in ways that can be related to disease in humans, including life long elevations of blood pressure and altered glucose-insulin metabolism in the offspring. ${ }^{22}$

\section{Mother's body composition and diet}

The availability of nutrients to the fetus is determined by the mother's body composition at conception and her diet in pregnancy. In early studies in Britain there were few data on mothers. Cohorts that include this information as well as having detailed measurements of body size at birth have now been identified in Europe as well as in the developing world, and include mothers who are chronically malnourished. Preliminary findings suggest that many babies today may be malnourished and at increased risk of coronary heart disease and non-insulin dependent diabetes either because their mothers are too thin, or too fat, or eat unbalanced diets. The offspring of women who are thin, as measured by skinfold thickness, tend to have raised blood pressure ${ }^{23}$ while the offspring of mothers with a high body mass index have increased rates of coronary heart disease and non-insulin dependent diabetes. ${ }^{124}$ Imbalance in the mother's protein and carbohydrate intake is associated with raised blood pressure in the offspring. ${ }^{19}$

\section{Childhood growth}

Studies in Helsinki have shown that the path of growth through childhood modifies the risk of disease associated with size at birth. ${ }^{25}$ The highest death rates from coronary heart disease occurred in men who were thin at birth but had accelerated weight gain in childhood. We do not yet know whether this association is because of the pathological effects of a high fat mass persisting into adult life, deleterious effects of catch up growth, or the intrauterine resetting of endocrine axes that control growth. It suggests that while the primary prevention of coronary heart disease and non-insulin dependent diabetes may ultimately depend on changing the body composition and diets of young women, more immediate benefit may come from preventing imbalances between prenatal and postnatal growth among children.

\section{Primary prevention}

To reduce chronic disease we need to understand how the human fetus is nourished and how malnutrition changes its physiology and metabolism. Fetal development is governed by complex, non-linear systems. Components of these systems interact, and the systems will have generic properties that do not depend on the details of their components. ${ }^{26} \mathrm{We}$ cannot solve our problems by reductionist science alone, but need to combine this with further clinical and epidemiological research.

\section{DAVID J P BARKER}

MRC Environmental Epidemiology Unit,

Southampton General Hospital,

Southampton SO16 6YD, UK

email:david.barker@mrc.soton.ac.uk

1 Barker DJP, Osmond C, Winter PD, Margetts B, Simmonds SJ. Weight in infancy and death from ischaemic heart disease. Lancet 1989;ii:577-80.
Barker DJP, Fall C, Osmond C, et al. Fetal and infant growth and impaired Barker DJP, Fall C, Osmond C, et al. Fetal
glucose tolerance. BMF 1991;303:1474-5.

3 Law CM, Shiell AW. Is blood pressure inversely related to birth weight? The strength of evidence from a systematic review of the literature. 7 Hypertens 1996;14:935-41.

4 Barker DJP. Fetal origins of coronary heart disease. BMF 1995;311:171-4. 5 Leon DA, Koupilova I, Lithell HO, et al. Failure to realise growth potential in utero and adult obesity in relation to blood pressure in 50 year old Swedish men. BMF 1996;312:401-6.

6 Rich-Edwards JW, Stampfer MJ, Manson JE, et al. Birth weight and risk of cardiovascular disease in a cohort of women followed up since 1976. BMf 1997;315:396-400

7 Leon D, Lithell HO, Vagero D, et al. Reduced fetal growth rate and increased risk of death from ischaemic heart disease: cohort study of 15000 Swedish men and women born 1915-29. BMf 1998;317:241-5.

8 Harding JE, Johnston BM. Nutrition and fetal growth. Reprod Fertil Dev 1995;7:539-47.

9 Ravelli ACJ, van der Meulen JHP, Michels RPJ, et al. Glucose tolerance in adults after prenatal exposure to the Dutch famine. Lancet 1998;351:1737.

10 Barker DJP. Mothers, babies and health in later life. Edinburgh: Churchill Livingstone, 1998.

11 Phillips DIW, Barker DJP, Hales CN, Hirst S, Osmond C. Thinness at birth and insulin resistance in adult life. Diabetologia 1994;37:150-4

12 Barker DJP, Martyn CN, Osmond C, Hales CN, Fall CHD. Growth in utero and serum cholesterol concentrations in adult life. BMF 1993;307:1524-7.

13 Martyn CN, Meade TW, Stirling Y, Barker DJP. Plasma concentrations of fibrinogen and factor VII in adult life and their relation to intra-uterine growth. Br F Haematol 1995;89:142-6.

14 Dicke JM. Poor obstetrical outcome. In: Pauerstein CJ, ed. Clinical obstetrics. New York: John Wiley and Sons, 1987:421-39.

15 Fall CHD, Stein CE, Kumaran K, et al. Size at birth, maternal weight, and non-insulin dependent diabetes in South India. Diabet Med 1998;15:220-7.

16 McCance DR, Pettitt DJ, Hanson RL, Jacobsson LTH, Knowler WC, Bennett PH. Birth weight and non-insulin dependent diabetes: thrifty genotype, thrifty phenotype, or surviving small baby genotype? BMf 1994; genotype, th

17 Barker DJP, Martyn CN, Osmond C, Wield GA. Abnormal liver growth in utero and death from coronary heart disease. BMF 1995;310:703-4.

18 Barker DJP, Bull AR, Osmond C, Simmonds SJ. Fetal and placental size and risk of hypertension in adult life. BMF 1990;301:259-62.

19 Campbell DM, Hall MH, Barker DJP, Cross J, Shiell AW, Godfrey KM. Diet in pregnancy and the offspring's blood pressure 40 years later. $\mathrm{Br} \mathcal{F}$ Obstet Gynaecol 1996;103:273-80.

20 Morton NE. The inheritance of human birth weight. Ann Hum Genet 1955; 20:123-34

21 Brooks AA, Johnson MR, Steer PJ, Pawson ME, Abdalla HI. Birth weight: nature or nurture? Early Hum Dev 1995;42:29-35.

22 Langley SC, Jackson AA. Increased systolic blood pressure in adult rats induced by fetal exposure to maternal low protein diets. Clin Sci 1994;86: 217-2.

23 Clark PM, Atton C, Law CM, Shiell A, Godfrey K, Barker DJP. Weight gain in pregnancy, triceps skinfold thickness and blood pressure in the offspring. Obstet Gynaecol 1998;91:103-7.

24 Forsen T, Eriksson JG, Tuomilehto J, Teramo K, Osmond C, Barker DJP. Mother's weight in pregnancy and coronary heart disease in a cohort of Finnish men: follow up study. BMF 1997;315:837-40

25 Eriksson JG, Forsen T, Tuomilehto J, Winter PD, Osmond C, Barker DJP. Catch-up growth in childhood and death from coronary heart disease: a longitudinal study. BMF 1999;318:7-11.

26 Goldberger AL. Non-linear dynamics for clinicians: chaos theory fractals, and complexity at the bedside. Lancet 1996;347:1312-14. 


\section{Evidence for using nebulised antibiotics in cystic fibrosis}

Standards of care for patients with cystic fibrosis (CF) have been defined largely on the basis of "best practice", an accolade awarded to treatment regimens showing low chronic pulmonary infection rates, greatest patient longevity, and least patient morbidity. While acknowledging the wisdom accrued through clinical experience, paediatricians caring for children with CF are fighting for limited resources and must convince purchasers, who stroll the fashionable catwalk of evidence based medicine, of the scientific basis of our demands. They ask, "Where's the beef?" For the use of nebulised antibiotics in CF care we can reply only that we have a lot of "topside" but few "prime cuts".

Clinical trials, the results of which affect all of our prescription practices, have been generally parochial in conception, bedevilled by small patient numbers, and underpowered, partly reflecting patient recruitment problems for research into an illness that affects only a small minority of the population and, until recently, a lack of multicentre trials. In his meta-analysis of the benefits and risks of nebulised antibiotic treatment in CF, Mukhopadhyay et al suggested that a definitive study would need 500 patients, the minimum that would allow for imbalances in patient characteristics that are not amenable to adjustments in the analysis. ${ }^{1}$ In Ramsey's study of TOBI, a preservative free preparation designed for nebulisation, over $80 \%$ of almost 500 patients completed the trial, ${ }^{2}$ but the most comprehensive published multicentre study at the time of writing has only 71 patients. ${ }^{3}$ The antibiotics studied (gentamicin, tobramycin, colistin, ceftazidime), the antibiotic dose ( $20 \mathrm{mg}$ to $600 \mathrm{mg}$ of aminoglycoside), the type of nebuliser used, and the length of treatment have varied, making comparison between trials difficult.

\section{Rationale for nebulised antibiotics}

$\mathrm{CF}$ is a multisystem disease but morbidity and mortality closely correlate with progressive pulmonary damage, most often caused by chronic Pseudomonas aeruginosa endobronchial infection. Persisting infection promotes chronic airway inflammation and progressive lung destruction. While intravenous antipseudomonal aminoglycoside antibiotics are fundamental to the treatment of this infection, decreasing the pulmonary bacterial load and improving lung function, ${ }^{4}$ they do not penetrate well into sputum, peak levels approximating to $12 \%$ of the serum concentration. ${ }^{5}$ Aminoglycoside activity is further compromised by biological antagonism in sputum. Half of a gentamicin dose added to CF sputum may be bound by extracellular neutrophil DNA and the altered ionic environment interferes with drug accumulation by the bacteria, significantly decreasing its bactericidal activity. ${ }^{6}$ In vitro, an aminoglycoside bactericidal effect can only be reliably produced with concentrations 25 times the minimum inhibitory concentration (MIC). ${ }^{5}$ To achieve such high drug concentrations in sputum in vivo by intravenous antibiotic delivery would increase unacceptably the potential for nephrotoxicity and ototoxicity. Aerosol delivery could provide a high concentration at the desired site with minimal absorption and therefore low risk of toxicity. ${ }^{78}$

The widespread use of nebulised antibiotics in the management of patients with CF has evolved from three landmark publications; Hodson et al in 1981, Littlewood et al in 1985, and Valerius et al in 1991..$^{9-11}$ These studies showed that twice daily inhalations improved respiratory function and decreased hospital admissions, ${ }^{9}$ decreased the frequency of positive $P$ aeruginosa cultures in recently colonised patients, ${ }^{10}$ and increased the chances of eradicating this organism when used to treat early infection in combination with oral ciprofloxacin. ${ }^{11}$

Aerosol delivery of antipseudomonal antibiotics has been widely used in Europe for over a decade, and is becoming increasingly popular in the USA where significant results have been obtained in trials of preservative free tobramycin (TOBI). It is a good time to look at the available evidence for its efficacy in maintaining respiratory function, treating acute exacerbations, and eradicating early $P$ aeruginosa colonisation.

\section{Treatment of patients with chronic $P$ aeruginosa infection}

In 1981 Hodson et al compared nebulised gentamicin $80 \mathrm{mg}$ and carbenicillin $1 \mathrm{~g}$ (both bid) with placebo in a double blind crossover trial in 20 adult patients over a one year period. ${ }^{9}$ During active treatment patients showed improved respiratory function, felt better, and were hospitalised less frequently. Subsequent studies emphasised these positive findings: enhanced lung function tests, ${ }^{312-14}$ slower decline in respiratory function, ${ }^{13}{ }^{15-18}$ decreased hospital admission rates, ${ }^{312} 1518$ improved clinical score, ${ }^{17} 18$ better weight profile, ${ }^{12141518}$ and decreased P aeruginosa density, ${ }^{314}$ exotoxin A or elastase. ${ }^{18}$ Patient numbers in these studies were small (nine to 41 ) and treatment length varied from three to over 32 months. Antibiotics used were ceftazidime, gentamicin and carbenicillin, colistin and tobramycin. Study designs were crossover, placebo controlled, and open label.

Only Ramsey et al's paper ${ }^{3}$ can stand alone as evidence based research. Otherwise we need to turn to Mukhopadhyay et al's meta-analysis to distil the evidence that confirms the benefit of nebulised antibiotics in CF care. ${ }^{1}$ Nine of 14 clinical trials were rejected because they lacked appropriate randomisation or failed to describe adequately outcome measures. These were defined in the metaanalysis as the number of acute pulmonary exacerbations, alterations in lung function, the number of patients with an altered pseudomonas respiratory load, alterations in the number of patients with resistant $P$ aeruginosa, and the incidence of auditory, renal or respiratory side effects. The analysis of the five qualifying papers concluded that nebulised antibiotics significantly reduced respiratory $P$ aeruginosa load and the frequency of respiratory exacerbations requiring systemic antibiotic treatment, and significantly increased lung function. The only adverse finding was a possible increase in in vitro bacterial resistance.

Ramsey et al's studies of aerosolised tobramycin allow us to make evidence based decisions about clinical and bacteriological efficacy. ${ }^{23}$ In a multicentre, double blind, placebo controlled trial, 71 patients received half strength physiological saline or $600 \mathrm{mg}$ TOBI in $30 \mathrm{ml}$ half strength saline delivered by ultrasonic nebuliser. ${ }^{3}$ The drug dose was chosen to attain a sputum concentration of at least $400 \mu \mathrm{g} / \mathrm{g}$ - that is, 10 -fold the MIC of tobramycin susceptible $P$ aeruginosa. This sputum concentration is necessary to prevent bacterial growth. ${ }^{5}$ Group 1 received tobramycin for 28 days and placebo for 56 days, and group 2 received tobramycin for 56 days followed by placebo for 28 days. Quinine was added to placebo and drug to mask differences in taste. Nephrotoxicity was monitored by serum creatinine concentrations and urine analysis, ototoxicity by auditory acuity and vestibular function tests, and adherence by urine quinine concentrations. Sixty six patients completed the trial. 
After 28 days, pulmonary function, expressed as a percentage of the predicted values, showed a 6-13 percentage point improvement in respiratory function in the active compared to placebo treatment periods: $\mathrm{p}<0.001$ for forced expiratory volume in one second $\left(\mathrm{FEV}_{1}\right)$ and forced expiratory flow $\left(\mathrm{FEF}_{25-75 \%}\right)$, and $\mathrm{p}=0.014$ for forced vital capacity (FVC). At the end of the three month trial the magnitude of the treatment effect had fallen to between 4-6 percentage points. The increase for $\mathrm{FEV}_{1}$ and $\mathrm{FEF}_{25-75 \%}$ remained significant at $\mathrm{p}=0.002$ and $\mathrm{p}=0.001$, respectively, but the difference between placebo and tobramycin for FVC was not significant. The results at three months possibly reflect the greater use of oral and intravenous antibiotics in the placebo periods $(p=0.006)$. Tobramycin also decreased the sputum density of $P$ aeruginosa by a factor of $100(\mathrm{p}<0.001)$ as well as the frequency of acute respiratory exacerbations $(p=0.06)$. Adjustments for age, sex, study centre, baseline lung function, and adherence did not affect the outcome data. There were no toxic effects but delivery of $600 \mathrm{mg}$ tobramycin by ultrasonic nebuliser poses problems of cost, patient inconvenience, and difficulties with nebuliser maintenance, and achieves higher than needed sputum aminoglycoside concentrations. ${ }^{14} 19$

Two subsequent phase III, multicentre, randomised, placebo controlled, double blind studies of TOBI compared $300 \mathrm{mg}$ of drug to a quinine based placebo, each in $5 \mathrm{ml}$ of quarter strength saline administered twice daily for 10-15 minutes via a Pari LC Jet Plus nebuliser and Pulmo Aide compressor. ${ }^{2}$ The $300 \mathrm{mg}$ dose has $>90 \%$ probability of achieving a peak sputum concentration at least 10 -fold greater than the maximal MIC of the patients' $P$ aeruginosa isolates. ${ }^{19}$ Patients received three treatment cycles over 168 days, each cycle consisting of 28 days with nebulisation followed by 28 days without. The on-off protocol design was based on evidence showing some treatment effect persisting at 28 days after stopping nebulised tobramycin, animal toxicology studies that showed resolution of any histological changes by that time, and because of the possibility of such a regimen minimising the potential for encouraging bacterial tobramycin resistance and increasing patient adherence (Ramsey BW. Presented at the 22nd European Cystic Fibrosis Conference, Berlin, June 1998). Adaptive randomisation ensured a balance between treatment groups for age, disease severity, sputum production, centre, concomitant recombinant human deoxyribonuclease (Pulmozyme; Roche Products Ltd, Welwyn Garden City, Herts, UK) inhalation, and the MIC of tobramycin susceptible $P$ aeruginosa. The treatment effect was defined as the mean relative change with active treatment minus the mean relative change with placebo from baseline at the end of the third treatment cycle. Over $80 \%$ of 491 patients enrolled completed the trial.

Nebulised tobramycin significantly improved respiratory function. The treatment effect for $\mathrm{FEV}_{1}$ was about $12 \%$ $(\mathrm{p}<0.001)$ evident after the first cycle and maintained throughout the study. Colony forming units per gram of sputum fell significantly $(\mathrm{p}<0.001)$. Hospital admissions and the need for intravenous antibiotic treatment fell compared to placebo $(\mathrm{p}=0.014)$, a difference that started to show at four weeks. Lung function data are now available for up to 12 months of treatment in over 250 patients and show maintenance of improvement at about $10 \%$ above baseline (Ramsey BW, June 1998). Nebulised tobramycin exerts a positive effect even in patients established on Pulmozyme treatment.

Safety of long term nebulised aminoglycosides

The main safety concerns centre on the risk of ototoxicity from aminoglycosides, nephrotoxicity from aminoglyco- sides and colistin, increased $P$ aeruginosa antibiotic resistance that may compromise choices for intravenous antibiotic courses, and superinfection with naturally resistant organisms (such as Burkholderia cepacia, Alcaligenes xylosoxidans, Stenotrophomonas maltophilia, and Aspergillus species). There was no detectable ototoxicity or nephrotoxicity with tobramycin doses up to $600 \mathrm{mg}$ tid when auditory acuity, vestibular function tests, serum creatinine, and urine analysis were used as monitoring tools. ${ }^{3}$ Systemic drug absorption from nebuliser delivery is minimal, ${ }^{8} 1920$ but aminoglycoside toxicity remains a risk with prolonged treatment. Urinary N-acetyl-B-D-glucosaminidase concentrations, a sensitive indicator of tubulointerstitial lesions, show a straight forward dose-response relation with inhaled gentamicin. ${ }^{21}$

Most studies report no increased resistance to the nebulised antibiotic ${ }^{3}{ }^{15-17}$ and no increased new infection with multiresistant organisms. ${ }^{3} 1317$ MacLuskey et al documented resistance developing in four of 12 patients receiving nebulised tobramycin for a mean of 32 months but in none of 12 controls. ${ }^{13}$ Any observed resistance is mostly minimal and transitory. ${ }^{1214} 18$

\section{Nebulised antibiotics in the treatment of acute respiratory exacerbations}

A small study comparing inhaled (eight patients) with intravenous (eight patients) antibiotic treatment for acute pseudomonas related pulmonary deterioration showed improvement and similar responses in both groups. ${ }^{22} \mathrm{~A}$ retrospective study of nebulised tobramycin for two weeks for acute $P$ aeruginosa infections had encouraging results. ${ }^{23}$ These have not been followed up in adequately powered randomised controlled trials and no conclusions can be drawn.

No study has shown benefit from adding inhaled antibiotics to routine intravenous treatment for acute respiratory exacerbations. ${ }^{24} 25$

\section{Nebulised antibiotics in the treatment of new $P$ aeruginosa infection}

Stephens and colleagues ${ }^{25}$ and Semsarin ${ }^{23}$ observed eradication of $P$ aeruginosa infection in studies of inhaled antibiotics in acute pulmonary deterioration. Littlewood and colleagues ${ }^{10}$ showed that inhaled colistin given soon after the first pseudomonas isolation can decrease the number of organisms isolated, the frequency of isolation, and in some cases eradicate the infection. The Copenhagen centre progressed this knowledge and in 1991 described how chronic pseudomonas infection can be largely prevented by combined oral ciprofloxacin and nebulised colistin each given for three weeks. ${ }^{11}$ Further experience suggests that three months of high dose combination treatment is more effective in preventing or at least delaying chronic infection. ${ }^{26}$ The argument for this use of nebulised antibiotic stands on the excellent results achieved, but criticism can be and is directed at the use of historic controls. The recommendation to follow the Copenhagen protocol is not evidence based as there are no randomised controlled trials, but the results are so formidable that such a study is unlikely to receive ethical approval, even if anyone wished to do it.

\section{Conclusion}

We cannot precisely know for any individual patient how much of the nebulised antibiotic is delivered to the lungs, nor exactly where it will be deposited. Sputum drug concentrations are only a rough guide. We do not know from where the sputum has been expectorated, nor how much of the antibiotic in the sputum is from the upper airways. Nonetheless, nebulised antibiotics can improve lung 
function, slow the rate of respiratory decline, and decrease the need for intravenous treatment. In combination with oral ciprofloxacin, nebulised colistin can eradicate early $P$ aeruginosa infection. Aerosolised antibiotic treatment appears safe in short term trials but long term safety data are not available and patients should be monitored routinely.

It is with interest and anticipation that studies with the Halolite nebuliser (Medic-Aid Ltd, Bognor Regis, West Sussex, UK) are awaited. Timing of antibiotic delivery to the first part of the inspiratory cycle should improve drug deposition and efficacy, ${ }^{8}$ reduce waste, and possibly improve compliance. Patient adherence to nebulised antibiotics delivered with standard equipment is likely to be only about $60 \% .{ }^{27}{ }^{28}$ We still do not know the minimum effective dose for nebulisation. Individual practices vary between $80 \mathrm{mg}$ and $300 \mathrm{mg}$ bid for aminoglycosides. Colistin is empirically prescribed at doses between $0.5 \mathrm{MU}$ and $2 \mathrm{MU}$ according to the child's weight. The Halolite, if fulfilling its promise, will necessitate revision of dosage schedules.

Nebulised antibiotic treatments in CF have progressed from a good idea derived from clinical experience to a more scientific approach to drug dosage and delivery. Only the preservative free tobramycin has been studied in an adequately powered trial, but many others document significant clinical and microbiological response to less expensive drug formulations - that is, the standard preparations for intravenous use delivered as an aerosol; to evaluate TOBI fully we need a direct comparison between them.

S P CONWAY

Consultant Paediatrician and Lead Clinician in CF Services, St Fames's and Seacroft University Hospitals,

Leeds LS14 6UH, UK

1 Mukhopadhyay S, Singh M, Cater JI, Ogston S, Franklin M, Olver RE. Nebulised anti-pseudomonal antibiotic therapy in cystic fibrosis: a meta-analysis of beneifts and risks. Thorax 1996;51:364-8

2 Ramsey B. Saftey and efficacy of tobramycin solution for inhalation in patients with cystic fibrois: the results of two phase III placebo controlled patients with cystic fibrois: the results of two phase 111
clinical trials. Pediatr Pulmonol Suppl 1997;14:137-8.

3 Ramsey BW, Dorkin HL, Eisenberg JD, et al. Efficacy of aerosolised Ramsey BW, Dorkin HL, Eisenberg JD, et al. Efficacy of aerosolised
tobramcyin in patients with cystic fibrosis. N Engl f Med 1993;328:1740-6. 4 Regelmann WE, Elliott GR, Warwick WJ, Clawson CC. Reduction of sputum Pseudomonas aeruginosa density by antibiotics improves lung function in cystic fibrosis more than do bronchodil

physiotherapy alone. Am Rev Respir Dis 1990;141:914-21.
5 Mendelman PM. Smith AL, Levy J, Weber A, Ramsey B, David RL. Aminoglycoside penetration, inactivation, and efficacy in cystic fibrosis sputum. Am Rev Respir Dis 1985;132:761-5.
6 Levy J, Smith AL, Kenny MA, Ramsey B, Schoenknecht FD. Bioactivity of gentamicin in purulent sputum from patients with cystic fibrosis or bronchiectasis: comparison with activity in serum. F Infect Dis 1983;148: 1069-76.

7 Le Conte P, Potel G, Peltier P, et al. Lung distribution and pharmacokinetics of aerosolized tobramycin. Am Rev Respir Dis 1993;147:1279-82.

8 Ilowite JS, Gorvoy JD, Smaldone GC. Quantitative deposition of aerosolized gentamicin in cystic fibrosis. Am Rev Respir Dis 1987;136:1445-9.

9 Hodson ME, Penketh, Batten JC. Aerosol carbenicillin and gentamicin treatment of Pseudomonas aeruginosa infection in patients with cystic fibrosis. Lancet 1981;ii;1137-9.

10 Littlewood JM, Miller MG, Ghonheim AT, Ramsden CH. Nebulised colomycin for early pseudomonas colonisation in cystic fibrosis [letter]. Lancet $1985 ; \mathrm{i}: 865$.

11 Valerius NH, Koch C, Hoiby N. Prevention of chronic Pseudomonas aeruginosa colonisation in cystic fibrosis by early treatment. Lancet 1991;338: $725-6$.

12 Stead RJ, Hodson ME, Batten JC. Inhaled cetazidime compared with gentamicin and carbenicillin in older patients with cystic fibrosis infected with Pseudomonas aeruginosa. Br 7 Dis Chest 1987;81:272-9.

13 MacLusky IB, Gold R, Corey M, Levison H. Long-term effects of inhaled tobramycin in patients with cystic fibrosis colonized with Pseudomonas aeruginosa. Pediatr Pulmonol 1989;7:42-8.

14 Smith AL, Ramsey BW, Hedges DL, et al. Saftey of aerosol tobramycin administration for 3 months to patients with cystic fibrosis. Pediatr Pulmonol 1989;7:265-71.

15 Wall MA, Terry AB, Eisenberg J, McNamara M. Inhaled antibiotics in cystic fibrosis [letter]. Lancet 1983;i:1325.

16 Kun P, Landau LI, Phelan PD. Nebulised gentamincin in children and adolescent with cystic fibrosis. Aust Paediatr f 1984;20:43-5.

17 Jensen T, Pedersen SS, Garne S, Heilmann C, Hoiby N, Koch C. Colistin inhalation therapy in cystic fibrosis patients with chronic Pseudomonas aeruginosa lung infection. F Antimicrob Chemother 1987;19:831-8.

18 Steinkamp G, Tummler B, Gappa M, et al. Long-term tobramycin aerosol therapy in cystic fibrosis. Pediatr Pulmonol 1989;6:91-8.

19 Eisenberg J, Pepe M, Williams-Waren J, et al, and the Aerosolized Tobramycin Study Group. A comparison of peak sputum tobramycin concentration in patients with cystic fibrosis using jet and ultrasonic nebulizer systems. Chest 1997;111:955-62.

20 Mukhopadhyay S, Baer S, Blanshard J, Coleman M, Carswell F. Assessment of potential ototoxicity following high-dose nebulized tobramycin in patients with cystic fibrosis. F Antimicrob Chemother 1993;31:429-36.

21 Ring E, Eber E, Erwa W, Zach MS. Urinary N-acetyl-B-D-glucosaminidase activity in patients with cystic fibrosis on long term gentamicin inhalation. Arch Dis Child 1998;78:540-3.

22 Cooper DM, Harris M, Mitchell I. Comparison of intravenous and inhalation antibiotic therapy in acute pulmonary deterioration in cystic fibrosis [abstract]. Am Rev Respir Dis 1985;131:A242.

23 Semsarin C. Efficacy of inhaled tobramycin in cystic fibrosis. F Paediatr Child Health 1990;26:110-11.

24 Schaad UB, Wedgewood-Krucko J, Suter S, Kramer R. Efficacy of inhaled amikacin as adjunct to intravenous combination therapy (ceftazidime and amikacin) in cystic fibrosis. F Pediatr 1987;111:599-605

25 Stephens D, Garey N, Isles A, Levison H, Gold R. Efficacy of inhaled tobramycin in the treatment of pulmonary exacerbations in children with cystic fibrosis. Pediatr Infect Dis 1983;3:209-11.

26 Frederiksen B, Koch C, Hoiby N. Antibiotic treatment of initial colonization with Pseudomonas aeruginosa postpones chronic infection and prevents deterioration of pulmonary function in cystic fibrosis. Pediatr Pulmonol 1997;23:330-5.

27 Abbott J, Dodd M, Bilton D, Webb AK. Treatment compliance in adults with cystic fibrosis. Thorax 1994;49:115-20.

28 Conway SP, Pond MN, Hamnett T, Watson A. Compliance with treatment in adult patients with cystic fibrosis. Thorax 1996;51:29-33

See related article page 348
Before Ruth Bishop's identification in Melbourne of human rotavirus in 1973, paediatricians could offer only platitudes by way of explanation when confronted with young children with acute diarrhoea. Since then it has become clear that rotavirus is the most common cause of gastroenteritis in children under 2 years of age living in either developed or developing countries. ${ }^{1}$ Its pathogenic mechanisms have been largely elucidated, mainly by studying an analogous infection in piglets caused by transmissible gastroenteritis agent. ${ }^{2}{ }^{3}$ Rotavirus probably causes diarrhoea by increasing the turnover of enterocytes along the villus axis, leading to the population of blunted villi by immature cells that are incapable of normal absorption, and are more crypt-like and secretory in nature. ${ }^{4-6}$ Rota- virus can also reduce sucrase-isomaltase expression in human enterocytes by blocking sucrase-isomaltase transport to the apical membrane without apparent cell destruction. Reduction in activity is correlated to rotavirus induced alterations in the enterocyte cytoskeleton. ${ }^{7}$ There is also a single unconfirmed report of elaboration of a secretagogue by rotavirus: purified NSP4 (non-structural glycoprotein of rotavirus) potentiates chloride secretion by a calcium dependent signalling pathway. ${ }^{8}$

In some children a clinical episode indistinguishable from acute gastroenteritis is followed by protracted diarrhoea, so called post-gastroenteritis syndrome. This is more likely to occur in developing countries, where pre-existing malnutrition and enteropathies may lead to 
protracted diarrhoea in $8-20 \%$ of children initially presenting with acute gastroenteritis. ${ }^{9}$ In developed countries this happens in up to $5 \%$ of cases, and its causes are far from clear. ${ }^{10}$ Secondary lactose intolerance may occur, and many children exhibit an intolerance to cows' milk protein and often several other proteins. ${ }^{10}{ }^{11}$ Management is pragmatic, and comprises mainly nutritional support. Most children in developed countries survive, but in developing countries mortality is still high. ${ }^{12}$

A recent report from the Melbourne group now suggests that persistent rotavirus infection may play a greater role in post-gastroenteritis syndrome and protracted diarrhoea than previously thought. ${ }^{13}$ Until now, rotavirus excretion was generally thought to stop within 10 days of the onset of symptoms in most children, and within 20 days of onset in all. ${ }^{14}{ }^{15}$ Enzyme immunoassay (EIA) is the technique commonly used for detection of rotavirus in stool, but reverse transcriptase-polymerase chain reaction (RT-PCR) is up to 25 times more sensitive than EIA in detecting rotavirus in serially diluted faecal suspensions. It has both higher sensitivity and specificity. ${ }^{17}$ Using an RT-PCR technique, Bishop's group studied the duration of rotavirus excretion in 37 children admitted to hospital with acute rotavirus infection. ${ }^{13}$ Excretion ceased within 10 days in 17 children and within 20 days in 26 of the 37 children. However, extended excretion between 25-57 days was seen in 11 children. Only one child seemed to have been re-infected with rotavirus. In contrast, rotavirus excretion estimated by EIA ranged from 4-29 days, and only 12 children had detectable excretion between 10 and 29 days. Extended excretion of rotavirus was significantly linked with intermittent antirotavirus IgA coproantibody boosts. Most of these boosts were associated with rotavirus excretion. Eight of the 11 children with extended rotavirus excretion between 25 and 57 days developed mild diarrhoea and vomiting associated with excretion or coproantibody boosts during the 100 days' surveillance.

It is clear that prolonged rotavirus excretion is not only a feature of immunodeficency ${ }^{18}$ but is also seen in about one third of immunocompetent young children. Intermittent mild diarrhoea seen in significantly increased numbers of children excreting rotavirus for one to two months could explain some cases of post-gastroenteritis syndrome. Moreover, children excreting rotavirus for prolonged periods could become reservoirs of human rotavirus and contribute to its survival between epidemics. As new diagnostic procedures indicate that rotavirus infection may be the cause of protracted diarrhoea in some children, who may have otherwise undetected infection, an effective rotavirus vaccine becomes even more important.

M SOOD

I W BOOTH

University of Birmingham,

Institute of Child Health,

Whittall Street, Birmingham, B4 6NH, UK

email:i.w.booth@bham.ac.uk

1 De Zoysa, Feachem RV. Interventions for the control of diarrhoeal disease among young children: rotavirus and cholera immunization. Bull WHO 1985;63:569-83.

2 Hamilton JR. The pathophysiological basis for viral diarrhoea: a progress report. F Pediatr Gastroenterol Nutr 1990;2:150-4.

3 Rhoads JM, MacLeod RJ, Hamilton JR. Diminished brush border membrane Na-dependent L-alanine transport in acute viral enteritis in membrane Na-dependent L-alanine transport in
piglets. F Pediatr Gastroenterol Nutr 1989;9:225-230.

4 Davdison GP, Barnes GL. Structural and functional abnormalities of the small intestine in infants and young children with rotavirus enteritis. Acta small intestine in infants and youn
Paediatr Scand 1979;68:181-6.

5 Collins J, Candy DCA, Starkey WG, Spencer AJ, Osborne MP, Stephen J. Disaccharidase activities in small intestine of rotavirus infected suckling mice: a histochemical study. F Pediatr Gastroenterol Nutr 1990;11:395-403.

6 Spencer AJ, Osborne MP, Haddon J, et al. X-ray microanalysis of rotavirusinfected mouse intestine: a new concept of diarrhoeal secretion. 7 Pediatr Gastroenterol Nutr 1990;10:516-28.

7 Jourdan N, Brunet JP, Sapin C, et al. Rotavirus infection reduces sucrase-isomaltase expression in human intestinal epithelial cells by perturbing protein targeting and organization of microvillar cytoskeleton $\mathcal{F}$ Virol 1998;72:7228-36.

8 Ball JM, Tian P, Zeng CQ, Morris AP, Estes MK. Age dependent diarrhoea induced by a rotaviral non-structural glycoprotein. Science 1996;272:101-

4.

World Health Organization. Persistent diarrhoea in children in developing countries. Report of a WHO meeting. $\mathrm{WHO} / \mathrm{CCD} / 88.27$. Geneva: World Health Organization, 1988.

10 Guandalini S. Prolonged diarrhoea: aetiology and pathogenesis. Diarrhoeal disease. Nestle nutrition workshop series 1997;38:153-66.

11 Walker-Smith JA. Cow's milk intolerance as a cause of postenteritis diarrhoea. $\mathcal{F}$ Pediatr Gastroenterol Nutr 1982;1:163-73.

12 Victora CG, Huttly SR, Nobre LC, Barros FC. Deaths due to dysentery, acute and persistent diarrhoea among Brazilian infants. Acta Paediatr Suppl 1992;381:7-11.

13 Richardson S, Grimwood K, Gorrell R, Palombo E, Barnes G, Bishop R. Extended excretion of rotavirus after severe diarrhoea in young children. Lancet 1998;351:1844-8.

14 Nagayoshi S, Yamaguchi H, Ichikawa T, et al. Changes of the rotavirus concentration in faeces during the course of acute gastroenteritis as determined by the immune adherence haemagglutination test. Eur f Pediatr 1980;134:99-102.

15 Wilde J, Van R Pickering, Eiden J, Yolken RH. Detection of rotavirus in the day care environment by reverse transcription polymerase chain reaction. $\mathcal{F}$ Infect Dis 1992;166:507-11.

16 Buesa J, Colomina J, Raga J, Prat J. Evaluation of reverse transcription and polymerase chain reaction (RT/PCR) for the detection of rotavirus: applications of the essay. Res Virol 1996;147:353-61

17 Masendycz PJ, Palombo EA, Gorrell RJ, Bishop RF. Comparison of enzyme immunoassay, PCR and type specific cDNA probe technique for identification of group A rotavirus gene 4 types (P types). $\mathcal{F}$ Clin Microbiol 1997;35:3104-8

18 Booth IW, Chrystie IL, Levinsky RJ, Marshall WC, Pincott J, Harries JT. 